\title{
Sociologia do Autor: biografia e trajetória de Darcy Ribeiro
}

Ana Crhistina Vanali ${ }^{1}$

RESUMO: esse artigo fornece alguns apontamentos sobre a trajetória intelectual de Darcy Ribeiro e sua contribuição para o pensamento social brasileiro a partir da análise da obra autobiográfica "As Confissões" publicada em 1997.

Palavras-chave: Darcy Ribeiro. Biografia. Pensamento Social.

ABSTRACT: this article provides some notes on the intellectual history of Darcy Ribeiro and his contribution to Brazilian social thought from the analysis of the autobiographical book "The Confessions" published in 1997.

Key-words: Darcy Ribeiro. Biography. Social thought.

"Fracassei em tudo o que tentei na vida.

Tentei alfabetizar as crianças brasileiras e não consegui.

Tentei salvar os índios, não consegui.

Tentei fazer uma universidade séria e fracassei.

Tentei fazer o Brasil desenvolver-se autonomamente e fracassei.

Mas os fracassos são minhas vitórias. Eu detestaria estar no lugar de quem me venceu."

(Parte do discurso proferido por Darcy Ribeiro quando do recebimento do título de Doutor Honoris Causa da Sorbonne em 1978)

Graduada em Ciências Sociais pela UFPR. Mestre em Antropologia Social pela UFPR. Doutoranda em Sociologia pela UFPR. Bolsista CAPES/PDSE na Universidade Nova de Lisboa. Endereço eletrônico: anacvanali@yahoo.com.br 
Darcy Ribeiro (1997) registrou em Confissões, escrito quando o câncer que o matou já o havia condenado ao recolhimento forçado, não só os enredos de sua vida pessoal, mas também o testemunho de um homem público apaixonado pela terra em que nasceu e pela qual mantinha viva toda esperança de um futuro promissor. Mineiro de Montes Claros, nascido em 26 de outubro de 1922, Darcy Ribeiro foi um intelectual múltiplo, ou, como gostava de enfatizar, "viveu muitas vidas", entre elas na etnologia, educação, literatura e política. Formado em Ciências Sociais pela Escola de Sociologia e Política de São Paulo (1946) com especialização em Antropologia, trabalhou como etnólogo do Serviço de Proteção ao Índio. Nesse período fundou o Museu do Índio e criou o Parque Nacional do Xingu. Romancista, publicou, entre outros, Maíra (1976); O Mulo (1981); Utopia Selvagem (1982); Migo (1988). Na educação, com Anísio Teixeira, participou da defesa da escola pública; criou a Universidade de Brasília, sendo seu primeiro reitor; foi ministro da educação de João Goulart (1961) e chefe da Casa Civil, tendo sido um dos coordenadores das reformas estruturais. Com os direitos políticos cassados com o Golpe Militar (1964), exilou-se. Retornando ao Brasil, foi anistiado em 1980 e eleito vice-governador do Rio de Janeiro (1982), acumulando o cargo de secretário de Estado de Cultura, onde gestou e dirigiu a implantação dos CIEP's - Centros Integrados de Educação Pública. Em 1987, teve uma efêmera passagem por Minas Gerais, no então governo Newton Cardoso, como secretário especial para a implantação de escolas de tempo integral. Em 1990, 
elegeu-se senador da República; entre diversas investiduras, elaborou a Lei de Diretrizes e Bases da Educação Nacional (Lei $\mathrm{n}^{\circ}$ 9394), sancionada em 20 de dezembro de 1996, conhecida como Lei Darcy Ribeiro.

Essa "vivência de muitas vidas" apontada por Darcy Ribeiro nos remete à proposta de Burawoy e Braga (2009), que defendem a ideia de uma "prática sociológica" engajada com diferentes públicos extra-acadêmicos e que consiga conjugar o rigor de uma sociologia profissional com a intervenção no espaço público. Assim, a trajetória de Darcy Ribeiro pode ser considerada como um exemplo dessa sociologia pública. Temos um intelectual pensando o país, seja atuando em academias e institutos, seja na universidade, em partidos ou inserido no aparelho de Estado. Ele buscou se inscrever na esfera pública, formulando e disputando projetos sobre o futuro da nação, desempenhando papel de destaque no processo da modernização brasileira. Analisar sua trajetória nos leva a refletir sobre as possibilidades conceituais e potenciais para se pensar o tema da inserção pública dos intelectuais, especificamente em nosso país ${ }^{2}$.

2 Consultar o artigo BRAGA, Ruy; GARCIA, Sylvia G.; MELlO E SILVA, Leonardo. Sociologia pública: considerações a partir do Brasil. In: BRAGA, Ruy; BURAWOY, Michael (Org.). Por uma Sociologia Pública. São Paulo: Alameda, 2009, p. 253-265. Esse artigo dedica-se à discussão da sociologia pública no Brasil analisando as trajetórias intelectual e política de dois representantes da sociologia crítica e militante: Florestan Fernandes e Francisco de Oliveira. Suas trajetórias institucionais se mesclam com trajetórias institucionais significativas para o desenvolvimento da sociologia pública no país, como as da USP, da Sudene e do Cebrap. 
A narrativa autobiográfica de Confissões pode ser considerada um espaço privilegiado de constituição do sujeito e de experiências de subjetividade. Essa narrativa busca dar sentido a sua vida individual, marcada por experiências múltiplas e heterogêneas, construindo a imagem de um intelectual engajado e multifacetado que tinha uma posição nada convencional em relação aos padrões acadêmicos vigentes a partir da segunda metade da década de 1960. Ressaltamos que tanto quanto a vida narrada, narrativa e narrador não escapam do condicionamento social, pois o indivíduo é sempre resultado de uma construção histórica e cultural. Darcy Ribeiro não poupou esforços para legitimar a figura de um intelectual indignado, seja com os rumos tomados pela antropologia brasileira, aos seus olhos cada vez mais "academicista" e descomprometida com seus sujeitos de pesquisa, seja pela situação política do Brasil, seja pela educação no país, seja ainda pela situação precária à qual foram conduzidas as populações indígenas. É difícil questionar a figura do intelectual "engajado e multifacetado", misto de antropólogo, político, educador e escritor que, de fato, marcou sua trajetória. Mas não podemos esquecer que a estrutura narrativa dos textos autobiográficos expressa um embate entre lembrança e esquecimento, a partir do qual é construída a memória; assim, não é difícil supor que Darcy Ribeiro tenha privilegiado, em sua narrativa, certos acontecimentos biográficos em detrimento de outros, conforme sugere Kofes (2001). 


\section{Algumas narrativas sobre a trajetória de Darcy Ribeiro}

Para a identificação de Darcy Ribeiro e de suas principais vivências em cada um dos seus campos de atuação ${ }^{3}$ temos uma vasta literatura; algumas obras serão apresentadas em seguida, não somente para compreender melhor o autor e suas realizações, mas também para buscar elementos que contribuíram marcadamente para a formação de seu pensamento político e para a construção de sua obra intelectual, buscando os elementos que possam contribuir para o modo como o autor pensou e interpretou a realidade social.

O trabalho biográfico de Guilherme Azevedo (2002), publicado como parte da coleção "Rebeldes brasileiros: homens e mulheres que desafiaram o poder" (Volume 2), organizada pela revista Caros Amigos, se dedica especificamente a traçar uma cronologia da vida do autor, bem como a exaltar seus feitos e modos de pensar. A principal contribuição de Guilherme Azevedo é que ele traz de forma bastante sintética e precisa a cronologia da vida de Darcy Ribeiro.

Mércio Gomes (2000), ao contrário de ser uma publicação reduzida e de caráter informativo, como a de Azevedo (2002), se propõe, além de uma cronologia da vida de Darcy Ribeiro, a uma análise pormenorizada de cada uma das fases de suas vivências. Constrói uma trajetória de seu pensamento sobre cada um de seus principais temas: os índios, a antropologia, a educação, a literatura e a política; redigindo, inclusive, uma pequena revisão das obras de Darcy

\footnotetext{
${ }^{3}$ Darcy Ribeiro foi etnólogo, antropólogo, educador, romancista e político.
} 
Ribeiro sobre cada um destes temas. No entanto, não escapa do caráter apologético de exaltação do autor e de seu pensamento. Contribui, contudo, para o recolhimento de elementos, de forma generalizada, sobre a vida e a obra de Darcy Ribeiro.

Destacando diferentes autores que se dedicaram a uma aproximação ao intelectual analisado, temos o livro de Vera Brant (2002). Muito belo, e por vezes emocionante, foi elaborado de forma a construir uma biografia romanceada de Darcy Ribeiro, levando-se em conta a proximidade de que pôde desfrutar a autora ao lado do seu "querido amigo" em questão. Apenas contribui para o conhecimento do autor na medida em que mostra sua vida cotidiana e seu modo de lidar com as pessoas e problemas, alguns deles de grande relevância para o Brasil e a vida política de sua capital, Brasília. Vez ou outra menciona feitos públicos de relevância por parte de Darcy Ribeiro sem os analisar pormenorizadamente, visto que a autora não se propõe a isso. Vera Brant apenas destaca algumas situações importantes da vida de Darcy e as insere em contextos reconstruídos para destacar a sua inegável veia poética, com a qual preenche os fatos descritos de pesada carga emotiva e os dota, invariavelmente, de grande beleza.

Eric Nepomuceno (2001) se dedicou a selecionar e organizar uma coletânea de frases e pensamentos de Darcy Ribeiro em que os elementos selecionados falam por si, de forma que a própria catalogação da obra indica o próprio Darcy Ribeiro como autor. Interessante porque congrega "frases de efeito" e geradoras de grandes 
polêmicas, algumas delas reconhecidas como marcas registradas de Darcy Ribeiro. Divide-se também por temas, como reflexões sobre a vida e contextos de vivência do autor, seu pensamento sobre ética acadêmica e política, sobre ideologias, índios, educação, o Brasil, o papel dos intelectuais e sobre a América Latina.

Conta-se também com a autobiografia do autor - Confissões ${ }^{4}$, importante por ser sua última obra, publicada postumamente ${ }^{5}$. Nesse livro o autor analisa sua infância, sua formação como intelectual, seus dilemas políticos relacionados ao comunismo, a Getúlio Vargas, ao trabalhismo, ao nacionalismo e ao desenvolvimentismo das décadas de 1950 e 1960, ao golpe militar, ao exílio em países latino-americanos, ao retorno ao Brasil com a anistia política, às experiências no governo do estado do Rio de Janeiro, na década de 1980, e no Senado, na década de 1990. Traz também uma revisão de toda a sua obra intelectual, com ponderações do autor sobre os objetivos de suas obras frente aos tempos e contextos em que foram escritas e, assim, sobre as necessárias revisões, adequações e atualizações de temas e conceitos, de acordo com as necessidades exigidas por novos tempos e contextos, com novos

\footnotetext{
${ }^{4}$ Obra de caráter autobiográfico, revela suas intimidades, seus sentimentos, suas frustrações e suas alegrias, mas não de maneira cronológica e sim de maneira descontínua. Coloca o que guardou seletivamente na sua memória, o que o impressionou e que serviu para a construção do seu EU. Traz à tona somente o que julgou conveniente e merecedor de registro (recurso válido e utilizado pelos que escrevem sobre si mesmos). Neste livro nos fala dos amores, dos amigos e das descobertas que fez durante sua vida.

${ }^{5}$ Darcy Ribeiro nasceu em 26 de outubro de 1922 na cidade de Montes Claros/MG e faleceu em 17 de fevereiro de 1997, em Brasília, aos 74 anos.
} 
problemas e possibilidades de atuação e intervenção na realidade brasileira e latino-americana. Sua leitura cativante exige, contudo, que se tenha conhecimento prévio da trajetória do autor, já que este tende a "endeusar-se". Sua leitura acrítica pode levar a análise de sua trajetória aos mesmos riscos assumidos pelos autores já mencionados, que sugerem ou induzem a uma visão exaltadora e pouco crítica de Darcy Ribeiro, de sua obra, de seus feitos e pensamentos.

Conta-se ainda com dois livros de entrevistas. Um com o próprio Darcy Ribeiro (Ribeiro, 1997a), em que, interpelado por Antonio Callado, Antonio Houaiss, Eric Nepomuceno, Ferreira Gullar, Oscar Niemeyer, Zelito Viana e Zuenir Ventura, o entrevistado fala de temas ainda não divulgados pela imprensa ou meios acadêmicos: assuntos ligados às suas vidas pessoal, política e intelectual. Sua principal contribuição refere-se ao tratamento da participação de Darcy Ribeiro na militância pelo Partido Comunista, nas décadas de 1940 e 1950 e, principalmente, da transição de sua filiação do comunismo ao trabalhismo nas décadas de 1950 e 1960. O livro traz ainda importantes avaliações sobre a dependência dos países latino-americanos em relação aos países desenvolvidos e, principalmente, da contradição entre Estados Unidos da América e América Latina no contexto das reformas neoliberais das décadas de 1980 e 1990.

Outro livro de entrevistas, organizado por Haydée Coelho (2003), como resultado de um trabalho de pós-doutorado pela Universidade da República Oriental do Uruguay, dedica-se a conseguir 
depoimentos de eminentes intelectuais latino-americanos que conviveram com Darcy Ribeiro, de 1964 a 1968, em seus quatro primeiros anos de exílio no Uruguai, mas que chega a transcender a momentos posteriores de seu exílio em outros países latino-americanos. Com esse trabalho temos a possibilidade de acompanhar a maneira como Darcy Ribeiro foi se incorporando a debates e se propondo a discutir problemas que, antes do exílio, se restringiam ao Brasil e, depois do exílio, ganharam abrangência latino-americana em suas dimensões política, econômica e social. O conteúdo desse trabalho mostra quais são os elementos e debates intelectuais em que Darcy Ribeiro se envolveu, em função do exílio, que o conduziram a refletir não somente sobre o Brasil e os países latino-americanos em seu conjunto, mas também sobre a identidade dos mesmos e destes com outros países menos desenvolvidos.

Vale destacar, ainda, que existe um conjunto de dissertações e teses de diferentes áreas do conhecimento que tratam sobre Darcy Ribeiro. Alguns exemplos: da área de filosofia, temos a dissertação de Lourenço Zancarano (1990), da antropologia, Danilo Lazzarotto (2000) e da educação, Paulo Tarso Gomes ${ }^{6}$ (1989). Como Darcy Ribeiro atuou em diferentes áreas, ele acaba se tornando um objeto de estudo atraente em diversos campos.

\footnotetext{
${ }^{6}$ Esse trabalho trata das reformas universitárias que Darcy Ribeiro realizou ao longo da década de 1970, com base na experiência da fundação da Universidade de Brasília, em 1961, e pode ser estendido a outras reformas universitárias realizadas por ele posteriormente.
} 
Em se tratando da educação, destacamos duas obras de Helena Bomeny. Na primeira, Bomeny (2001b) trata das propostas de modernização da educação brasileira operadas por três intelectuais da área: Anísio Teixeira, Darcy Ribeiro e Paulo Freire. Na segunda, Bomeny (2001a) trata da construção do pensamento educacional de Darcy Ribeiro. Cabe a Helena Bomeny a idéia de "intelectual militante" ou "intelectual engajado", referências fundamentais para o entendimento da vida e da obra de Darcy Ribeiro, que não concebe a atividade científica sem uma veia política marcadamente "militante e engajada”. Darcy Ribeiro tenta mostrar através de seus ensaios e obras literárias a sua interpretação da condição da América Latina, e como ela deveria "reinventar" sua identidade através de suas propostas de integração e formação de uma grande nação.

Darcy Ribeiro é considerado um intelectual múltiplo devido aos seus diferentes campos de atuação, seja na área da educação, nos seus ensaios literários, ou tratando de temas gerais, tudo isso contribuiu para a formação de seu pensamento. A projeção pública alcançada por ele e sua participação em momentos importantes da história brasileira já justificariam um trabalho biográfico. Darcy Ribeiro representa um daqueles poucos exemplos de intelectuais que se tornaram conhecidos também fora da sua disciplina. Tal fato se deve não somente à

\footnotetext{
${ }^{7}$ Dado o fato de não só vincular estritamente causas ideológicas a reiterados projetos de intervenção, como também o fato de que, em cada atividade que exercia, respaldarse de maneira marcante por convicções político-ideológicas sempre polêmicas e, por vezes, combativas e combatidas, e que exigiam, portanto, a militância.
} 
repercussão de seus escritos, mas também, e talvez sobretudo, às atividades de diversos matizes exercidas por ele no Brasil e no exterior - neste caso particularmente durante os anos em que se manteve exilado em países da América Latina - que acabaram por projetá-lo internacionalmente. Tudo isto vem contribuindo para associá-lo à imagem de um intelectual multifacetado, recorrentemente retratada em grande parte das narrativas sobre a sua trajetória. O próprio Darcy Ribeiro não foge à regra. Em várias ocasiões, quer em entrevistas, quer em textos autobiográficos, ele não poupou esforços para construir - ou reforçar - esta imagem em torno de seu próprio personagem. Mas não só. Quase sempre, tais narrativas procuram atribuir-lhe uma posição nada convencional em relação aos padrões do trabalho acadêmico então vigentes.

Contudo, a ênfase em tais atributos da personalidade de Darcy Ribeiro pode resvalar, com certa facilidade, para uma tentativa de apreender sua trajetória a partir de uma suposta excepcionalidade, particularmente em relação à academia. As violentas críticas que Darcy Ribeiro passou a dirigir publicamente aos seus pares a partir do final da década de 1970, aliadas à sua retomada da vida política, no princípio da década de 80, acabaram por contribuir significativamente para que a imagem de intelectual avesso a qualquer tipo de academicismo se tornasse indissociável de sua própria personalidade. Mais ainda, Darcy Ribeiro passou a ser comumente associado à figura do intelectual 
público, antes comprometido com um tipo de política tout à court do que com uma produção acadêmica no sentido estrito.

As pesquisas biográficas devem ter como ponto de partida antes um problema do que um personagem. No caso de Darcy Ribeiro, a reflexão deve ter como ponto de partida não a sua figura como "pai fundador" da antropologia no Brasil, nem tampouco partir de uma suposta exclusão de um campo intelectual ao qual ele, de fato, se contrapôs com extremado vigor, particularmente após o exílio. Trata-se de perguntar como e quando Darcy Ribeiro se tornou, de fato, um personagem à margem do mainstream da antropologia brasileira, perguntar em que medida ele escolheu ser um intelectual outsider.

\section{Considerações Finais}

A trajetória de Darcy Ribeiro, olhada mais de perto, deixa entrever não só a existência de um antropólogo cuja formação e atuação, particularmente entre o final dos anos 1940 e os anos 1960, se enquadravam com quase perfeição aos padrões de trabalho intelectual daquele período, como, principalmente, a de um indivíduo que buscou articular-se continuamente com o intuito de inserir-se em espaços sociais que nem sempre franquearam seu acesso. Tentativas que, em contextos distintos, tiveram maior ou menor sucesso e que, portanto, permitem situá-lo ora como um intelectual comum, ora como precursor, ora como marginal. É nesta multiplicidade de sentidos que pode se apreender a experiência social de Darcy Ribeiro - na análise da 
perspectiva de uma trajetória. Escrever uma biografia não é mais contar uma história individual concebida como do berço ao túmulo, mas sim buscar uma visão de conjunto, seguir um percurso e com isto tentar entender, a partir de uma dimensão diacrônica, como se articulam discurso, prática e obra do biografado num determinado período. Tratase ainda de uma trajetória apreendida a partir de um campo empírico específico que pode ser um acervo pessoal, documentos, correspondências, recortes de jornais, textos, etc. A trajetória emerge da análise desse material empírico, tendo sempre em mente que é necessário desnaturalizar esses arquivos e considerar as condições de sua construção, pois os documentos não são isentos de erros, imprecisões e omissões. Os documentos, embora digam muito, não dizem tudo sobre o biografado e muito menos sobre as circunstâncias nas quais ele viveu.

De acordo com Antonio Candido, ${ }^{8}$ Darcy Ribeiro "teve a capacidade de viver muitas vidas numa só". Em qualquer lugar que se procure saber algo sobre Darcy Ribeiro dificilmente se consegue escapar, à primeira vista, do que já, de tão recorrente, parece ter se tornado inerente à caracterização desse intelectual, e que se trata, exatamente, da multiplicidade de seus campos de atuação - foi etnólogo, antropólogo, educador, político, exilado, ensaísta, romancista, legislador, político e crítico social do Brasil, da América Latina e do

${ }^{8}$ No prefácio do livro de Darcy Ribeiro $O$ povo brasileiro: evolução e sentido do Brasil. São Paulo: Companhia das Letras, 1995. 
mundo. Em cada um destes campos de atuação ganhou grande repercussão. E, para se destacar nesses diferentes espaços, ele viveu vários contextos desde a década de 1940 até a sua morte.

Darcy Ribeiro via sua obra como fruto do esforço em conjugar o conhecimento de diferentes áreas de atuação. É difícil separar o autor da sua obra, já que ele se movia por uma convicção de que os dois interagem. E para participar de diferentes contextos e sob tantas perspectivas político-ideológicas em confronto, assumiu diferentes posturas. Com base nessas contraditoriedades foi questionado e banalizado, como um caso de intelectual a desconsiderar e, assim, foi também depreciado ou colocado em descrédito, principalmente pela comunidade acadêmica brasileira. Com relação a isso o próprio Darcy Ribeiro, que se orgulhava de mudar de conviç̧ões de acordo com o que acreditava serem as exigências de cada momento, se via como um "homem feito muito mais de dúvidas do que de certezas e estou sempre disposto a ouvir argumentos e a mudar de opinião. Tenho mudado muitas vezes na vida. Felizmente." (RIBEIRO, 1997, p. 309).

$\mathrm{O}$ que de fato importava para Darcy Ribeiro era defender suas causas. Ele próprio chegou a se definir, antes de tudo, como homem de fé e de partido, que fazia tanto política como ciência movido por razões éticas, defendendo causas as mais variadas possíveis com vistas a, antes de tudo, ser participante. Ser participante, influir sobre as pessoas, ajudar o Brasil a encontrar a si mesmo, libertar a América Latina da exploração - Darcy Ribeiro dizia que tinha o grande objetivo de intervir 
na realidade e, de acordo com o que acreditava, torná-la melhor, interferindo, via social ou política, positiva ou negativamente, mas sempre inferindo a sua marca. Um diálogo entre racionalidade e passionalidade acompanha seu discurso: causas racionais transformadas em causas passionais, grandes paixões perseguidas de maneira racionalizada para se tornarem realidade. Segundo Bomeny (2001a, p. 52):

Qualquer que seja o informe, o motivo de reflexão, o relato, percebemo-nos envolvidos em sua paixão exponencialista nas suas muitas formas de tradução: indignação, erotismo, paixão, raiva e melancolia (...) Lendo o mundo com as lentes da paixão, a Darcy nada era compreensível fora do registro da emoção. (...) Da Escola Livre de Sociologia, Darcy Ribeiro guardou mais que lembranças. Armazenou não apenas o acervo que foi cultivando ao longo da vida, mas também a marca de um confronto que nunca pôde resolver entre a atividade acadêmica e a militância. Caminhos suspeitos para ambas as adesões que supunha natural: os comunistas the cobrando ação, a academia lhe cobrando rigor e isenção. (...) A mudança de rumo com relação à causa indígena também recebeu em Darcy uma justificativa política. Deixa os estudos acadêmicos, mais do interesse dos antropólogos do que seus objetos de estudo, e passa a ser um 'combatente da causa indígena'. Sai da postura do etnólogo que busca o índio como quem vai ao primitivo, e presentifica sua ação, politizando-a como questão nacional (...) Conhecer modelos não implica a 
adoção desses modelos como projetos nacionais. E se acompanharmos a trajetória de Darcy percebemos muito rapidamente que o diletantismo não era propriamente o fundamento da sua curiosidade intelectual. Conhecer é intervir. O sentido político da atividade intelectual nunca lhe escapou. Ora, se tinha como projeto de vida intervir nos processos sociais e alterar seu curso, se sua estrada no mundo era política, isso se traduziu em uma adesão incondicional à matriz transformadora.

Ao longo de sua carreira de projetos realizados e não realizados, Darcy Ribeiro acreditava ter deixado como exemplo e solução para os problemas do Brasil, da América Latina e do mundo, a capacidade de se indignar: "Nós da América Latina, só podemos ser indignados ou resignados. Eu não vou me resignar nunca. ” (RIBEIRO, 1997, p. 269). E a partir da indignação, reivindicar, e se possível muito mais do que isso, realizar pequenas e grandes revoluções: "O mundo é um projeto que os homens poderiam fazer. A essência da natureza humana é que ela é utópica." (RIBEIRO, 1997, p. 327).

Darcy Ribeiro é um personagem intelectual bastante divulgado, porém pouco estudado no Brasil, sendo conhecido mais pela sua obra $O$ povo brasileiro, de 1995, ou por sua participação política no contexto brasileiro em nome de causas educacionais. Dentro da comunidade acadêmica brasileira, dificilmente se vincula Darcy Ribeiro como um importante teórico. Iniciamos esse exercício com a leitura da 
história de Darcy, narrada por Darcy ${ }^{9}$, depois partimos para algumas narrativas biográficas para melhor entender esse repensar de si mesmo que Darcy Ribeiro realiza. Assim, voltamos ao início, onde toda narrativa, autobiográfica ou não, é uma construção social, comportando, portanto, contestações e novas (re)interpretações. Esse pequeno exercício não foge à regra. Sem a pretensão de esgotar o assunto, mas sim de apresentá-lo, dotado de uma dose de objetividade procurando questionar, e não confirmar as suposições levantadas. Procuramos apontar que a biografia pode ser um objeto de estudo da Sociologia que deve mapear a tensão de cada campo em que o autor estudado estava ou está inserido. Discurso, conhecimento e realidade encontram-se inevitavelmente imbricados. Dessa perspectiva, a riqueza da trajetória de Darcy Ribeiro torna-se evidente, quer pelos fatos narrados em Confissões, quer pelas lacunas e pelos não-ditos que permitem uma (re)interpretação de momentos importantes da história brasileira que o influenciaram e foram por ele influenciados.

\section{Referências}

AZEVEDO, Guilherme. Darcy Ribeiro. In: Rebeldes brasileiros: homens e mulheres que desafiaram o poder. v. 2. São Paulo: Casa Amarela, 2002. p. 674-691.

BOMENY, Helena. Darcy Ribeiro: sociologia de um indisciplinado. Belo Horizonte: Editora UFMG, 2001a.

${ }^{9}$ RIBEIRO, Darcy. Confissões. São Paulo: Companhia das Letras, 1997. 
BOMENY, Helena. Darcy Ribeiro: sociologia de um indisciplinado. Belo Horizonte: Editora UFMG, 2001a.

BOMENY, Helena. Os intelectuais da educação. RJ: Jorge Zahar Editores, 2001b

BRANT, Vera. Darcy. São Paulo: Paz e Terra, 2002.

BURAWOY, Michel; BRAGA, Ruy (Org.). Por uma sociologia pública. São Paulo: Alameda, 2009.

COELHO, Haydée Ribeiro (Org). Las memorias de la memoria: el exilio de Darcy Ribeiro en Uruguay: entrevistas. Belo Horizonte: FALE/UFMG, 2003.

GOMES, Mércio Pereira. Darcy Ribeiro. São Paulo: Ícone, 2000.

GOMES, Paulo de Tarso. A Universidade em sociedades subdesenvolvidas: estudo das propostas de Darcy Ribeiro. Campinas: Dissertação - Mestrado em Educação. PUC-Campinas, 1989.

KOFES, Maria Suely. Uma trajetória em narrativas. Campinas: Mercado das Letras, 2001.

LAZZAROTTO, Danilo. A teoria de Darcy Ribeiro: evolução cultural da pedra lascada à cibernética. Ijuí: Editora UNIJUI, 2000.

NEPOMUCENO, Eric (Org.). Somos todos culpados: pequeno livro de frases e pensamentos de Darcy Ribeiro. Rio de Janeiro: Editora Record, 2001.

RIBEIRO, Darcy. Confissões. São Paulo: Companhia das Letras, 1997.

RIBEIRO, Darcy. Mestiço é que é bom. Rio de Janeiro: Paz e Terra, 1997a. 
RIBEIRO, Darcy. O povo brasileiro: evolução e sentido do Brasil. São Paulo: Companhia das Letras, 1995.

ZANCARANO, Lourenço. A filosofia da cultura na ciência da cultura de Darcy Ribeiro. Campinas: Dissertação de Mestrado em Filosofia. PUC-Campinas, 1990.

Recebido em 20/07/2015, aceito para publicação em 04/04/2016 